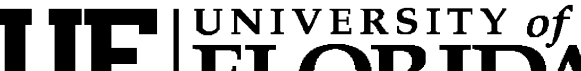 FLORIDA \\ IFAS Extension
}

\section{Best Management Practices in the Everglades Agricultural Area: Soil Testing 1}

\author{
S.H. Daroub, O.A. Diaz, T.A. Lang and M. Chen ${ }^{2}$
}

\section{Introduction}

The Everglades Agricultural Area (EAA) comprises an area of approximately 700,000 acres (280,000 ha) of organic soils planted mostly with sugarcane, with other crops such as winter vegetables, sod and rice grown on a lesser scale (Figure 1). The fundamental purpose of soil fertility has always been to quantify the ability of soils to supply nutrients required for optimum plant growth. The use of a "calibrated soil test" is considered an important tool used for nutrient management for field crops, and is also considered a "Best Management Practice" (BMP) for water quality improvement in the EAA basin that is worth five points toward the total of 25 points that each grower is required to implement in their farms (Sievers et al., 2003). The Everglades Soil Testing Laboratory (ESTL) at the Everglades Research and Education Center (EREC) in Belle Glade, Florida interprets soil test results to make fertilizer recommendations for crops grown in the organic soils of the EAA. The purpose of this document is to outline the process of soil testing as an important tool for both fertilizer recommendations and as a BMP in this region. This EDIS article is one in a series which attempts to explain in easily understandable terms the implementation methods and rationale behind the main $\mathrm{P}$ load reducing BMPs employed on EAA farms.

\section{Soil Testing}

Soil testing is defined as a chemical analysis to assess the plant-available nutrient status, salinity, and elemental toxicity of a soil. A broader definition of soil testing represents a program that includes interpretation, evaluation, fertilizer and amendment recommendations based on the result of chemical analyses and other considerations (Peck and Soltanpour, 1990). The use of soil testing represents perhaps the most significant practical application of our knowledge of soil science to land use management and should be viewed as an interpretative process, not simply as a series of laboratory methods. Since the late 1940s, soil testing has been widely accepted as an essential tool to formulate a sound lime and fertilizer program. The purpose of soil testing traditionally has been to provide a quantitative basis for soil management decisions related to agricultural systems. However, with increased emphasis on environmental quality and the rising cost of fertilizer materials, soil testing

1. This document is Fact Sheet SL-225, one of a series of the Soil and Water Science Department, Florida Cooperative Extension Service, Institute of Food and Agricultural Sciences, University of Florida. Original publication date July 2005. Visit the EDIS Web Site at http://edis.ifas.ufl.edu.

2. S. H. Daroub, Assistant Professor, O. A. Diaz, T. A. Lang, and M. Chen, Research Associates, University of Florida Institute of Food and Agricultural Science, Everglades Research and Education Center, Belle Glade, FL.

The Institute of Food and Agricultural Sciences (IFAS) is an Equal Opportunity Institution authorized to provide research, educational information and other services only to individuals and institutions that function with non-discrimination with respect to race, creed, color, religion, age, disability, sex, sexual orientation, marital status, national origin, political opinions or affiliations. U.S. Department of Agriculture, Cooperative Extension Service, University of Florida, IFAS, Florida A. \& M. University Cooperative Extension Program, and Boards of County Commissioners Cooperating. Larry Arrington, Dean 


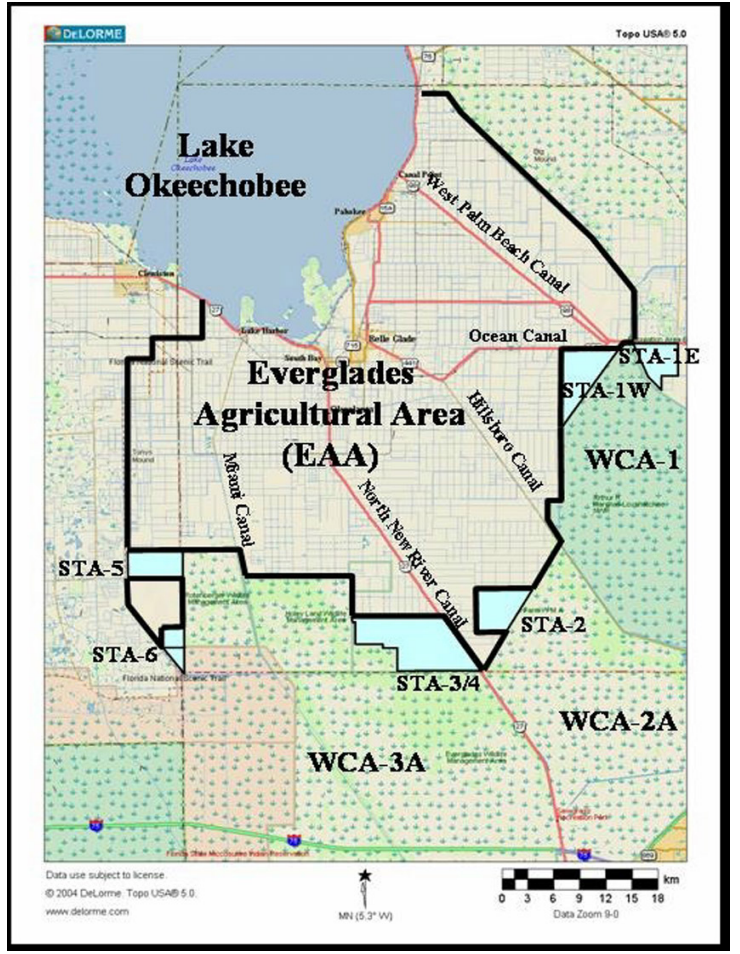

Figure 1. Map of the Everglades Agricultural Area (EAA) and surrounding Everglades Protection Area. Note: STA $=$ Stormwater Treatment Area; $W C A=$ Water Conservation Area.

is becoming an important tool to determine areas where adequate or excess fertilization has occurred.

\section{Soil Sample Collection and Submitting}

One of the most important aspects of soil testing is the collection of a soil sample that is representative of the tested area. Soil variability is a naturally occurring feature that significantly affects the reliability of soil testing for fertilizer recommendations. Wide variability occurs even in uniform fields. Althought the EAA is a relatively flat area, there exists natural soil variability that has further increased through the years by drainage, agricultural practices, and extensive construction of roads and canals (Diaz et al., 1992). Therefore, one should be aware of the main causes of soil variability during the collection of soil samples in the organic soils of the EAA.

\section{Collecting Soil Samples}

Variability of soil chemical properties is generally increased on cultivated fields. Cropping practices from the previous crop (such as fertilizer application) usually tend to superimpose additional heterogeneity on soil chemical properties (Peck and Soltanpour, 1990). To minimize the influence of soil variability due to previous management practices, fields to be sampled should be already cultivated and ready for planting before samples are taken. Areas near marl roads and ditch spoils should be avoided or sampled separately. Diaz et al. (1992) reported that contour maps of soil chemical properties from major soil series from the EAA showed that an area of approximately $130 \mathrm{ft}(40 \mathrm{~m})$ from the road and $82 \mathrm{ft}$ $(25 \mathrm{~m})$ from each side of field ditches should be avoided during soil sampling.

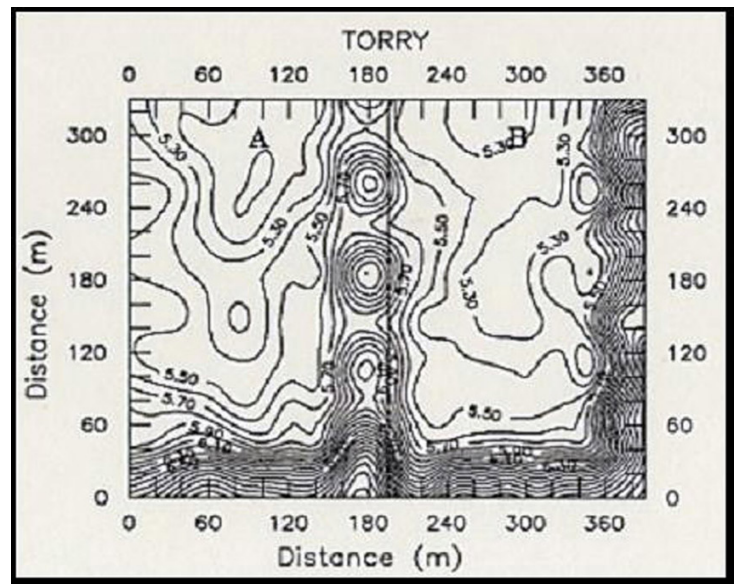

Figure 2.a

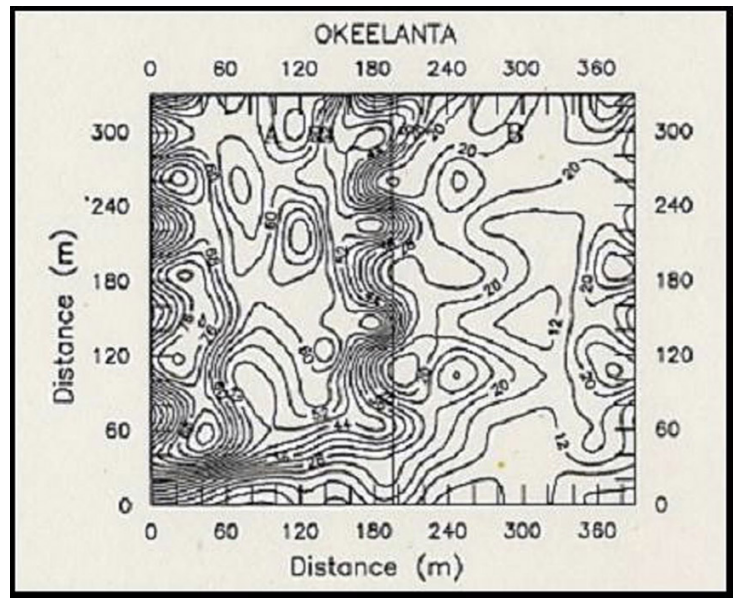

Figure 2.b

Figure 2. Contour maps showing infield variability of $A) \mathrm{pH}$ and $\mathrm{B}$ ) water extractable $\mathrm{P}(\mathrm{Pw})$ concentrations from a Torry and Okeelanta mucks from the EAA (Diaz et al., 1992). 
Figure 2 shows the effect of road and ditch spoils on soil pH (Fig. 2A) and the effect of fertilizer application from a previous crop on water extractable P (Fig. 2B). The ESTL recommends taking soil samples at a depth of 6 in $(15 \mathrm{~cm})$ at about $100 \mathrm{ft}(30$ $\mathrm{m})$ from the road near one end of the field, and continue collecting samples in zigzag fashion across the field, so as to have between 20 to 30 soil cores for a 40-acre field (Sanchez, 1990).

\section{Handling and Submitting Soil Samples}

Proper handling of the sample is also important to avoid contamination or to minimize changes in elemental concentrations before analysis (James and Wells, 1990). Handling includes collecting soil cores, mixing to prepare a composite sample, transporting from the field to the laboratory, followed by drying, grinding, and storing in the laboratory. One should use sampling and mixing tools made of materials that will not contaminate the soil (i.e., stainless steel or plastic). Once collected, individual soil cores from the area of interest are composited by combining them in a clean container, preferably made of plastic to avoid contamination. The soil cores should be thoroughly mixed. Then a sub-sample should be placed in a clean and properly labeled soil sample bag (Figure 3). Ziplock bags are recommended to use. Soil samples should be delivered to the ESTL or other soil testing laboratory facility as soon as possible after collection. Soil samples should not be left out in the sun or in enclosed spaces such as truck cabs for an extended period of time. Changes may occur due to high temperatures which will affect soil testing values. Soil samples should be brought, mailed, or submitted through the county extension agent to the ESTL (3200 E. Palm Beach Rd., Belle Glade, FL 33430-4702). Samples can also be submitted to other laboratories familiar with organic soils. Information including the name of the grower, mailing address, field location (township, range, and section number), past crop and fertilization history, and crop to be grown must be provided with every sampled submitted (Sanchez, 1990; Rice, 2005).

\section{Extraction and Chemical Analysis}

Plant-available nutrients are defined as the chemical form or forms of essential plant-nutrients in



Figure 3. Typical tools used to collect and prepare samples to be sent to the laboratory.

the soil whose variation in concentrations is reflected in changes in plant growth and yield (Peck and Soltanpour, 1990). The laboratory analysis is divided in two parts: extraction and measurement. Extraction involves the use of a chemical reagent solution to separate from the soil all or a fraction of the plant-available nutrients. Measurement is the determination of the amount of plant-available nutrient extracted. Some of the soil analysis by the ESTL include water and salt $\mathrm{pH}$, water extractable $\mathrm{P}$ $(\mathrm{Pw})$, and acetic acid extractable $\mathrm{P}(\mathrm{Pa}), \mathrm{K}, \mathrm{Ca}$, and $\mathrm{Mg}$. Analysis and final calculations are based on 0 to 6 in $(15 \mathrm{~cm})$ soil depth of air-dried samples (Sanchez, 1990; Rice, 2005).

\section{Interpretation}

For agricultural systems, a statistical correlation must exist between a soil test value and some aspect of plant response (e.g., crop yield), which can be used as the basis for soil test calibration. Yield responses from various rates of applied nutrients can then be related to the quantity of available nutrients indicated by the soil test. The accuracy with which a soil test value can be interpreted will depend on the kind and quality of the field research work on which the correlation are based. Some laboratories in addition to reporting exact measurements, classify the degree of nutrient sufficiency as low, medium, high, or excessive. Figure 4 is an example of the relationship between soil-test $\mathrm{P}$ and relative yields for crisphead lettuce. This figure indicates that the critical soil-test value for crisphead lettuce is $30 \mathrm{lbs}$ P/ac. Above a soil-test $\mathrm{P}$ index level of 30 , we would expect no response of lettuce to $\mathrm{P}$ fertilizer, and no $\mathrm{P}$ fertilizer will be recommended. Conversely, if the 
soil-test values are below the critical levels for a given nutrient, a fertilizer recommendation for that particular nutrient is provided.

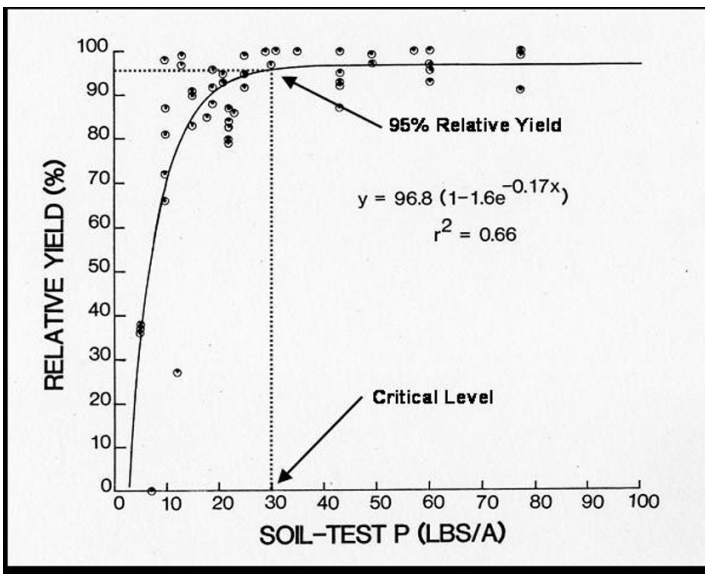

Figure 4. Response of crisphead lettuce to soil-test $P$ levels (Sanchez, 1990).

\section{Fertilizer Recommendation}

The final objective of the soil-testing program is to provide a fertilizer recommendation that is economically sound and environmentally friendly. Fertilizer recommendation for crops grown in the organic soils of the EAA is calculated by the ESTL. Soil test reports from the ESTL provide an index to the portion of the crop nutrient requirement that can be supplied from the soil. Based on these critical levels, fertilizer is recommended to supplement the soil fertility to obtain positive yield and quality responses. The critical nutrient levels used in the calculation of fertilizer recommendations for sugarcane and vegetables are based on several decades of research; however, more work is being done to improve the current recommendations (Anderson, 1985; Sanchez, 1990; Nagata et al., 1992; Hochmuth et al., 1994, Hochmuth et al., 1996). For nutrients that are known to have environmental impacts, such as $\mathrm{P}$, the use of a sound soil-testing program for fertilizer recommendations is fundamental to protect ground and surface water quality.

For detailed information on fertilizer recommendations in the EAA, the reader is advised to check the following extension publications (See References):
For fertilizer recommendations for sugarcane, check Anderson, D.L. 1985.

For fertilizer recommendation for sugarcane and other crops in the EAA, check Sanchez, 1990.

For fertilizer recommendation for crisp head lettuce grown on organic soils, check Hochmuth et al., 1994 extension publication at http://edis.ifas.ufl.edu/WQ114

For fertilizer recommendation on various vegetable crops, check Hochmuth et al., 1996 extension publication at http://edis.ifas.ufl.edu/CV008

\section{Summary}

Following is a summary of the steps to collect a representative soil sample for analysis:

1. Sample cultivated fields.

2. Stay away from ditches, banks, and roads.

3. Take 20 to 30 cores per 40 acre-block at a sampling depth of $15 \mathrm{~cm}$ (6 in). Take soil samples at about $30 \mathrm{~m}$ (100ft) from the road near one end of the field and continue in a zigzag fashion across the field, so as to have 20-30 soil cores per the 40 acre field.

4. Mix your core samples well in a plastic bucket to get a representative sample.

5. Transfer a sub-sample into a plastic bag; label your sample.

6. Submit your sample as soon as possible after collection to the Everglades Soil Testing Laboratory (ESTL) at 3200 E. Palm Beach Rd., Belle Glade, FL 33430-4702, or through the County Extension Agent. Indicate analysis required and crops to be grown.

7. Follow Fertilizer recommendations. Remember the use of a calibrated soil test is worth 5 points on the BMP list in the EAA. 


\section{Acknowledgements}

The authors are grateful for the financial support of the Everglades Agricultural Area-Environmental Protection District and the Florida Department of Environmental Protection for the preparation of this document and also conducting the associated BMP studies described within it.

\section{References}

Anderson, D.L. 1985. Sugarcane fertilization of muck and sandlands in south Florida. EREC Research Report EV-85-6.

Diaz, O.A., D.L. Anderson, and E.A. Hanlon. 1992. Soil nutrient variability and soil sampling in the Everglades Agricultural Area. Comm. Soil Sci. Plant Anal. 23:2313-2337.

Hochmuth, G., E. Hanlon, R. Nagata, G. Snyder, and T. Schueneman. 1994. Fertilization recommendations for crisphead lettuce grown on organic soils in Florida. Florida Extension Serv. SP 153. http://edis.ifas.ufl.edu/WQ114.

Hochmuth, G., E. Hanlon, G. Snyder, R. Nagata, and T. Schueneman. 1996. Fertilization of sweet corn, celery, romaine, escarole, endive, and radish on organic soils in Florida. Florida Extension Serv. Bull. 313. http://edis.ifas.ufl.edu/CV008.

Nagata, R.T., C.A. Sanchez, and F.J. Coale. 1992. Crisphead lettuce cultivar response to fertilizer phosphorus. J. Amer. Soc. Hort. Sci. 117:721-724.

James, D.W., and K.L. Wells. 1990. Soil sample collection and handling: Techniques based on source and degree of field variability. Pp: 25-44. In: R.L. Westerman (ed.) soil testing and plant analysis. $3^{\text {rd }}$ ed. Soil Science Society of America, Madison, WI.

Peck, T.R., and P.N. Soltanpour. 1990. The principles of soil testing. In R.L. Westerman (ed.) Soil Testing and Plant Analysis. Soil Science Society of America, Madison WI.
Rice, R.W. 2005. Soil Testing Laboratory

Procedures and Protocols. In process.

Sanchez, C.A. 1990. Soil-testing and fertilization recommendation for crop production on organic soils in Florida, University of Florida, Bull. 876, Gainesville, FL. 44 pp.

Sievers, P., D. Pescatore, S. Daroub, J.D. Stuck, J. Vega, P. McGinnes, and S. Van Horn. 2003. Performance and Optimization of Agricultural Best Management Practices. In Water Year 2002, Everglades BMP Program Annual Report, South Florida Water Management District, West Palm Beach, FL. 